\title{
AC 2011-1810: INCORPORATION OF THE DYE SENSITIZED SOLAR CELL RESEARCH RESULTS INTO SOLAR CELLS AND MODULES COURSE
}

\section{Lakshmi Munukutla, Arizona State University, Polytechnic campus}

Lakshmi Munukutla received her Ph.D. degree in Solid State Physics from Ohio University, Athens, Ohio and M.Sc and B.Sc degrees from Andhra University, India. She has been active in research and published several journal articles. She is a professor in the Department of Engineering Technology at Arizona State University. 


\title{
Incorporation of Dye Sensitized Solar Cell Research Results into Solar Cells and Modules Class
}

\begin{abstract}
Dye sensitized Solar Cells (DSSCs) fabrication technology is gaining momentum as a low cost and simple technology to convert solar energy into electricity. A systematic study of the DSSC fabrication procedure and its influence on the solar cell efficiency are presented in this paper. The significant process improvements made to enhance cell efficiency are: preparation of titanium dioxide $\left(\mathrm{TiO}_{2}\right)$ layer, $\mathrm{TiO} 2$ layer sintering, composition of the dye absorption solution and the sealant material thickness. The process optimization steps made in this study enhanced cell efficiency over $200 \%$ and significantly reduced process time. The paper describes incorporation of these research findings into the classroom, which include a few hands on activities for the students to gain better understanding of the cell parameters that control its performance. The understanding of converting solar energy into electricity is demonstrated using the Dye Sensitized solar cells. The infusion of research results into a course, Solar Cells and Modules at Arizona State University is a successful event.
\end{abstract}

\section{Introduction:}

The DSSCs are considered as third generation solar cells and as a member of the family of thin film solar cells that include: amorphous solar cells, Cadmium telluride (CdTe) and Copper Indium Gallium Selenide solar cells (CIS and/or CIGS) ${ }^{1,2}$. The third generation solar cell cost is predicted to be at least five times lower compared to the silicon solar cells and that triggered interest in the DSSCs. Dr. Michael Grätzels' work brought more attention to the DSSC and also thus is known as Grätzel cell ${ }^{3}$. However, Gerischer was the first one to study the semiconductor-electrolyte interface of the photoelectrochemical cells ${ }^{4,5}$. After the oil crisis in 1973, huge impetus was generated in exploring the photoelectrochemical cells to meet the energy challenges faced by the world.

The DSSCs are not free of challenges in spite of its simple fabrication procedure and low cost. The major challenges of DSSCs can be summarized as low efficiency, low stability and low scalability ${ }^{6}$. The efficiency is influenced by several factors, such as short circuit current $\left(\mathrm{I}_{\mathrm{sc}}\right)$, open circuit voltage $\left(\mathrm{V}_{\mathrm{oc}}\right)$, fill factor $(\mathrm{FF})$ and internal resistances. The conversion efficiency of the cell could be improved by reducing internal resistances. There are several ways to reduce the cell internal resistances: adjusting the thickness of the conducting layer on the electrode, modifying the roughness factor and reducing the gap between electrodes ${ }^{6}$. The use of electrolyte, which is chemically aggressive in the DSSC makes it difficult to use silver fingers for current collection and makes it difficult to scale up the cell ${ }^{6}$. The DSSCs stability study is not matured yet to predict its performance over long periods ( $>20$ years) similar to silicon based commercial solar cells. The cell has to withstand elevated temperatures, cyclic change in temperatures due to seasons, exposure to humidity and prolonged outside exposure are 
still to be explored. The DSSC sealing system including sealing material and sealing procedure need to be further investigated.

\section{DSSC Operation Principle:}

A DSSC comprises of a working electrode made of dye-sensitized $\mathrm{TiO}_{2}$ nanoparticles fabricated on a transparent conducting oxide (TCO), a Pt counter electrode, and an electrolyte containing iodide/triidode $\left(\mathrm{I}^{-} / \mathrm{I}_{3}^{-}\right)$redox couple. The photo conversion efficiency of DSSC is significantly dependent on the quality of $\mathrm{TiO}_{2}$ electrodes. The schematic representation of the DSSC is shown in Figure 1. A mesoporus oxide layer composed of nanoparticles is the heart of the DSSC and is sintered to achieve the electronic conduction. On the surface of this oxide layer is the monolayer of charge transfer dye. Due to photon excitation of the dye the electron is injected into the conduction band of the oxide. The excited dye replenishes the injected electron from the electrolyte $\left(3 \mathrm{I}^{-}-\rightarrow \mathrm{I}_{3}^{-}+2 \mathrm{e}^{-}\right)$such as the iodide/triiodide couple. The iodide-based electrolyte receives electrons from the external circuit and is regenerated by the reduction $\left(\mathrm{I}_{3}^{-}+2 \mathrm{e}^{-} \rightarrow 3 \mathrm{I}^{-}\right)$of the triiodide at the counter electrode ${ }^{7}$. The voltage of a DSSC corresponds to the difference between the Fermi level of the electron in the solid and the redox potential of the electrolyte. Hence, there is no permanent chemical transformation during the generation of electric power.



Figure 1: DSSC Operation Principle 


\section{DSSC Fabrication}

The key components of a DSSC structure are a working electrode made of dyesensitized $\mathrm{TiO}_{2}$ nanoparticles fabricated on a transparent conducting oxide (TCO), dye sensitizer, electrolyte and Pt counter electrode. The Figure 2 depicts key components of the DSSC. Each component plays a significant role and they are briefly described here. The $\mathrm{TiO}_{2}$ semiconductor has three functions in the dye-sensitized solar cell: it provides the surface for the dye adsorption, it functions as electron acceptor for the excited dye and it serves as electron conductor.

The dye is the photoactive element of the device, harvesting the incident light for the photon-to-electron conversion. Typically, the dye should ideally cover a wide range of the solar spectrum. Thus, ruthenium dyes are preferred because they adsorb throughout the visible spectrum (panchromatic) capture most of the sunlight. The electrolyte regenerates the oxidized dye after electron injection into the semiconductor, and transports the positive charge to the counter electrode. To function as dye mediator in DSSC, the redox potential of the electrolyte must be more negative than that of the oxidized dye. The mediator should not have any significant light absorption in the visible range, to avoid internal filter effects. The counter electrode is ideally a high conductivity material and is constituted by a glass coated transparent film deposited with a platinum layer. When a photon excites the dye molecule, it injects electrons into the semiconductor layer. After that, a redox reaction in the electrolyte $\left(3 \mathrm{I}^{-} \rightarrow \mathrm{I}_{3}^{-}+2 \mathrm{e}^{-}\right)$provides the electron back to the dye molecule. The triiodide in turn accepts electrons, and is reduced to iodine $\left(\mathrm{I}_{3}^{-}+2 \mathrm{e}^{-} \rightarrow 3 \mathrm{I}^{-}\right)$to regenerate the redox couple.

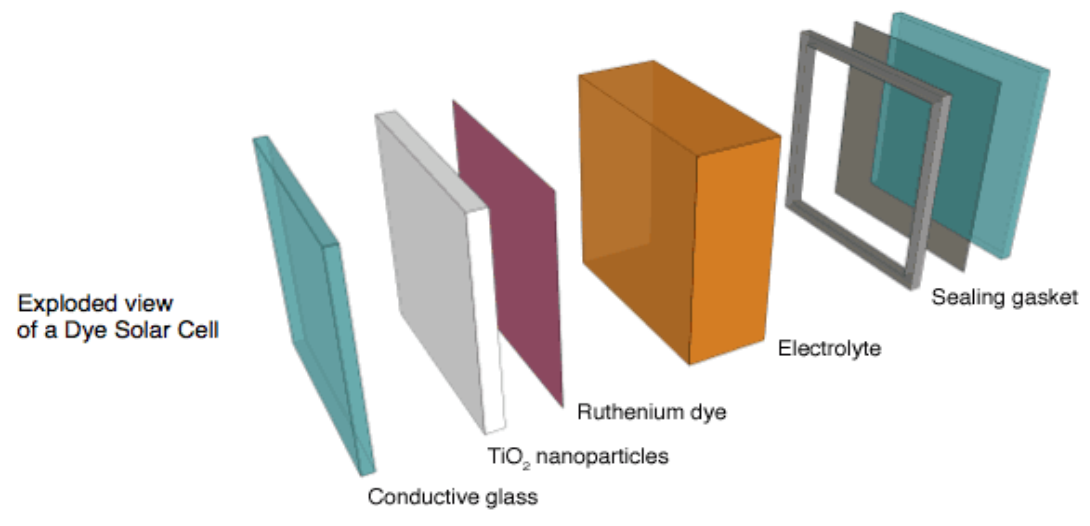

Figure 2: DSSC Components ${ }^{8}$

The fabrication procedure of DSSC consisted of eight steps and the sequence of these fabrication steps are illustrated in Figure 3. The total time spent to complete the cell fabrication is relatively small (three days). The fabrication process began with electrode preparation. The electrode preparation step involved determining the size of the electrode and cutting the electrode material to the required size and drilling a hole in the counter electrode for electrolyte injection. $\mathrm{TiO}_{2}$ coating on the working electrode and Platinum coating on the counter electrode were done on the same day. After coating processes, both electrodes were sintered together in the furnace. On the following day, only the working electrode was immersed into the Ruthenium dye solution for 24 hours. On the third day, the cell was assembled using $25 \mu \mathrm{m}$ thick commercial sealant material. 
After assembling the cell, electrolyte was injected through the hole from the counter electrode. The final step was to seal holes on the counter electrode using the hot gel gun.

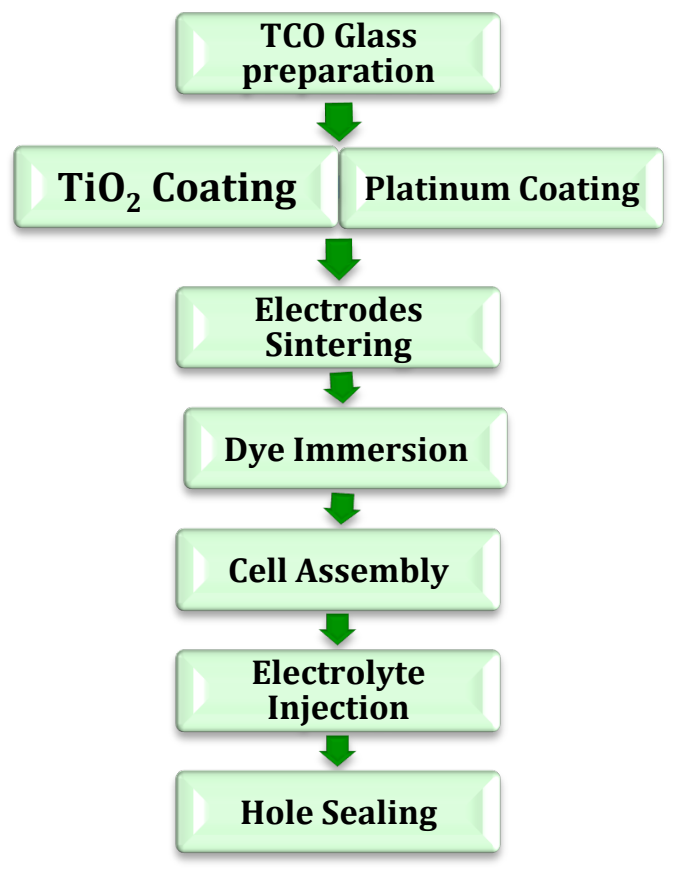

Figure 3: Cell Fabrication Steps

\section{DSSC Characterization}

The DSS cell was characterized using the simulated sun light at 1.5 AM with Xe Arc Lamp and power supply purchased from Newport and Parstat 2273 Advanced Electrochemical system to measure I-V curve and the impedance plot (Nyquist plot) are shown in Figure 4. The DSSC parameters $\mathrm{V}_{\mathrm{oc}}, \mathrm{I}_{\mathrm{sc}}$ and $\mathrm{FF}$ were extracted from the I-V curve to find the cell efficiency. The cell internal resistances are estimated from the Nyquist plot.

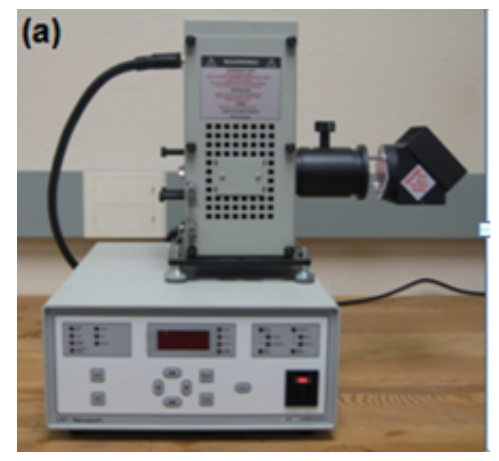

(b)

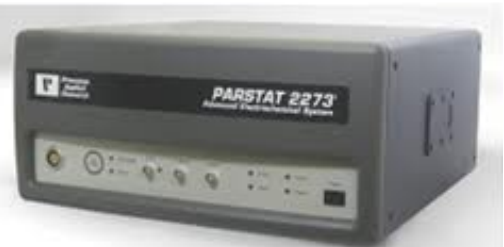

Figure 4: (a) Solar Simulator (b) Advanced Electrochemical System 


\section{Infusion of DSSC Research Results into Classroom}

The course suitable for integrating the DSSC research results is a required senior undergraduate course, Solar Cells and Modules for all students majoring in the BS degree concentration, Alternative Energy Technologies and as an elective for students from other majors. During fall semester 2010, the students in the class participated in characterizing the cells in the laboratory. In the lecture class theoretical discussion of the solar cell I-V characteristics and internal resistance influence on the I-V curve were covered. The DSSC's I-V characterization was performed using an equivalent circuit model that is shown in the Figure 5. The series and shunt resistances of the cell are primary contributors for the internal resistance. The Figure 6 illustrates the shift in I-V curve due to internal resistance and corresponding shifts in $\mathrm{V}_{\mathrm{OC}}, \mathrm{I}_{\mathrm{SC}}$ and Fill Factor (FF). The students were able to measure the I-V curves of various test cells. The graduate students involved in the DSSC research were kind to share their cells for this hands on activity. This experimental activity made it possible for the students to understand the concepts well compared to just theoretical discussion.

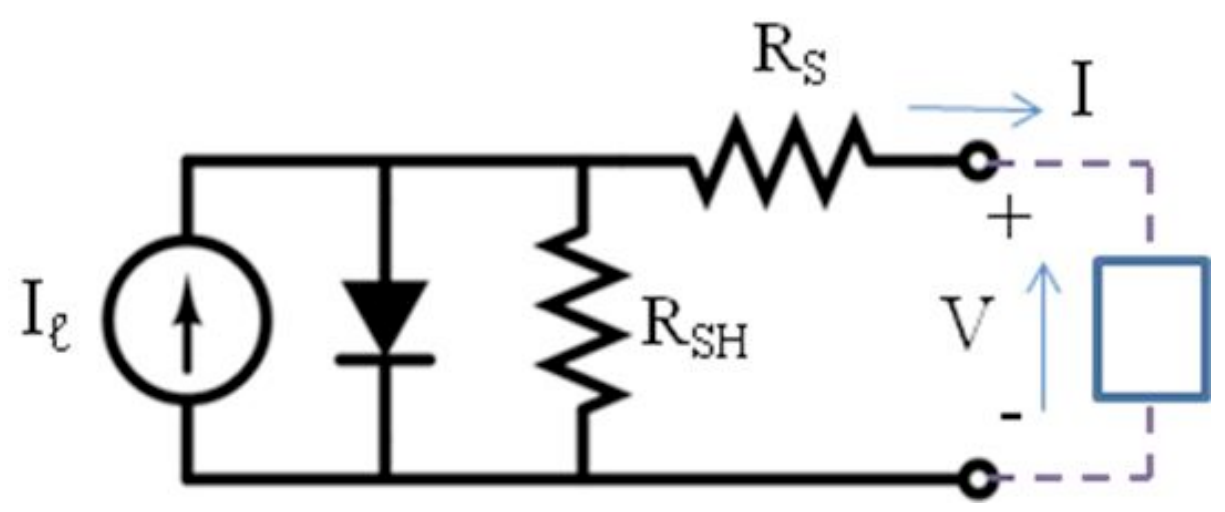

Figure 5: Equivalent circuit model used for the DSSC I-V characterization

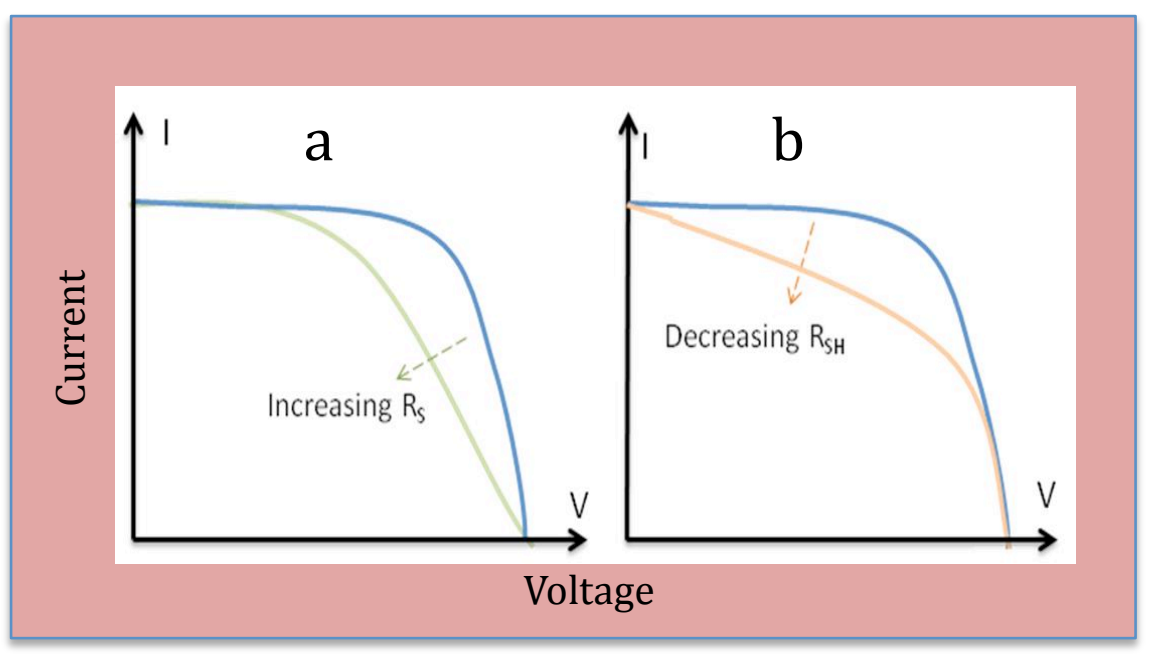

Figure 6: Illustration of the influence of increasing series resistance $\mathrm{R}_{\mathrm{s}}$ and decreasing shunt resistance $R_{\text {sh }}$ on the I-V curve of DSSC 
The research results obtained by the graduate student's work were used to explain the design characteristics of the solar cell and how the fabrication procedure influenced the device performance. The cell efficiency, $\eta$, was calculated using the equation below to determine the overall cell performance.

$$
\eta=\frac{P_{\max }}{P_{i n}}=\frac{I_{s c} * V_{o c} * F F}{P_{i n}}
$$

Where the Filter Factor, FF is given by

$$
F F=\frac{I_{m p} * V_{m p}}{I_{s c} * V_{o c}}
$$

The parameters: $\mathrm{P}_{\max }$ (maximum power point), Isc (short circuit current), Voc (open circuit voltage), Imp (current corresponding to the maximum power) and $\mathrm{V}_{\mathrm{mp}}$ (voltage corresponding to the maximum power point) were extracted from the I-V curve as illustrated in the Figure 7.

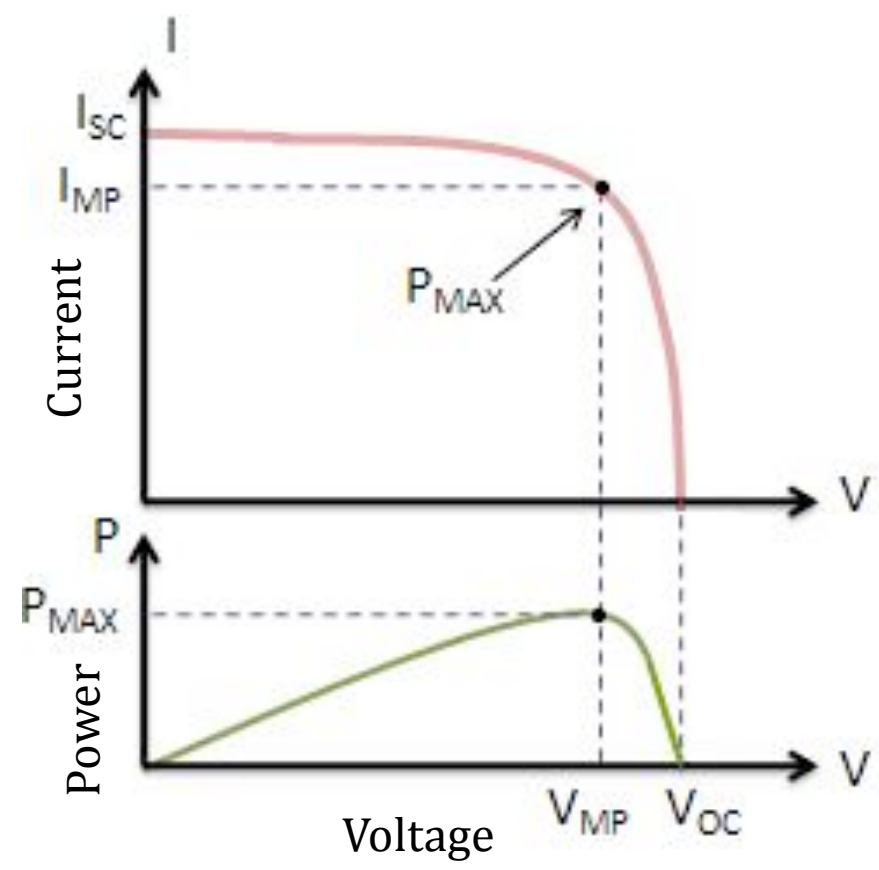

Figure7: Illustrates extraction of the parameters $\left(\mathrm{P}_{\mathrm{max}}, \mathrm{V}_{\mathrm{mp}}, \mathrm{I}_{\mathrm{mp}}, \mathrm{I}_{\mathrm{sc}}\right.$ and $\left.\mathrm{V}_{\mathrm{oc}}\right)$ from the measured I-V curve used to calculate the cell efficiency

The cell efficiency was improved over $200 \%$ by optimizing the parameters, such as $R_{s}$ and $R_{s h} V_{o c}, I_{s c}$, and Fill factor. Most of the optimization of cell parameters was 
achieved through improving the cell's fabrication process in particular the $\mathrm{TiO}_{2}$ layer coating and cell sealing process. These improvements reduced the internal resistance of the cell and consequently improved the cell efficiency.

The lab has only one experimental set-up for conducting research. Therefore, the class was divided into three groups with four members in each group. The characterization equipment is the only bottleneck and rest of the fabrication process could be conducted in parallel. The time required to fabricate a cell is not a long process, therefore, multiple groups could engage in fabrication process at a given time. However, consumables required for assembling the DSSCs are expensive. Therefore, the cells assembled for our research work were used for this study. The consumables required are: conductive electrodes, dye, $\mathrm{TiO}_{2}$ material, electrolyte, platinum solution, sealant material and these consumables are not cheap. To assemble five cells the cost of the consumables may range close to $\$ 3 \mathrm{~K}$. That is one of the reasons the characterization part was the only one tried in this study. To bear the cost of consumable one has to introduce a lab fee or some other means to cover the expenses. The costs of the Solar Simulator and Electrochemical system are around $\$ 9 \mathrm{~K}$ and $\$ 55 \mathrm{~K}$ respectively. In addition, we had a laser machine to design the cells and other automated equipment. If one has to start from scratch, the required investment may be close to $\$ 200-400 \mathrm{~K}$ excluding the consumables. The safety issues are less stringent and normal laboratory safety practices are adequate for fabricating the DSSCs. The idea that the paper emphasizes is that the research work conducted by the professor teaching the course can find its way into the classroom to provide better understanding of the concepts to enrich student learning.

The students stated that it was a very meaningful experience and they could understand the cell performance much better after performing this lab experiment. The students gained knowledge from this experience with regard to cell design and fabrication steps and how they could be optimized to enhance cell efficiency. Overall, this initial attempt in infusing the research results into a classroom is a success based on student reactions.

\section{Summary}

The Dye Sensitized Solar cell fabrication is simple and integrated into a classroom to provide practical experience to the students to grasp better understanding of the theory of the solar cell. The cell characterization experiment conducted by the students in the laboratory provided adequate explanation and reasoning how the internal resistances present in the cell could adversely impact the cell efficiency in support of the theory that was covered in the lecture class. Additionally, the process improvements made to enhance the cell efficiency by reducing the cell internal resistances were also demonstrated in the laboratory as solutions. However, if it is primarily aimed for teaching purpose only then cost of the equipment and consumables required for fabrication of the DSSCs are the financial challenges that the institution needs to address for suitability of its implementation. The future course offerings will include limited cell fabrication procedure to provide entire experience to the students. Additionally, incorporating 
research activities into the classroom enriched students learning and increased student motivation in the course.

Acknowledgements: The Solar simulator used in this work is procured using the NSF grant funding, Award \# 603478. The materials and other expenses incurred in this work are supported by the Research Incentive Distribution funds acquired by the author from ASU generated by the earlier funded projects.

\section{References}

1. S.R. Wenham, M.A. Green, M.E. Watt and R. Corkish, "Chapter 2:

Semiconductors and P-N Junctions," Applied Photovoltaics, Earthscan, pp.31-38, 2007.

2. S.Y. Lin, W.Y. Chou, Investigation of Pentacene/Perylene Derivative Based Organic Solar Cells, National Cheng Kung University, Tainan Taiwan, 2007.

3. Michael Grazel, Photoelectrochemical cells, Nature, Vol. 414, pp. 338-344, 2001.

4. W.H. Brattain, C.G.B. Garrett, Experiments on the interface between germanium and the electrolyte, Bell Syst. Tech. J., Vol.34, pp.129-176, 1955.

5. H. Gerischer, Electrochemical behavior of semiconductors under illumination, J. Electrochem. Soc., Vol.113, pp. 1174-1182, 1966.

6. W.J. Lee, E. Ramasamy, D.Y. Lee, J.S. Song, Glass frit overcoated silver grid lines for nano-crystalline dye sensitized solar cells, Journal of Photochemistry and Photobiology A: Chemistry Vol. 183, pp. 113-137, 2006.

7. Michael Gratzel, Review Dye-Sensitized Solar Cells, Journal of Photochemistry and Photobiology C, Photochemistry Reviews, Vol. 4, pp.145-153, 2003.

8. www.solaronix.com.

9. Barbé, Ch. J. et al., Nanocrystalline titanium oxide electrodes for photovoltaic applications, J. Am. Ceram. Soc. 80, 3157-3171 (1997). 